\title{
Exploring the Path of Implementing Rural Revitalization Strategy in Jilin Province
}

\author{
Hong Lv, Yue Zhao*
}

\author{
Changchun University of Technology, Changchun, China \\ *Corresponding author. Email: zy18243100009@163.com
}

\begin{abstract}
In order to solve the problems in the process of rural construction in Jilin Province, this paper will analyze the problems and propose corresponding countermeasures. Based on the development requirements of the times and the production peculiarities of rural Jilin Province, this paper draws the following conclusions. To realize rural revitalization, it is necessary to promote the priority development of agriculture and rural areas, create an integrated agricultural industrial system, promote the development of industrial integration and implement the talent path. It is hoped that to solve the problems of rural development and people's livelihood, so that farmers can have a real sense of gain, happiness and security, and to provide reference significance for other regions to solve the issues relating to agriculture, rural areas, and rural people.
\end{abstract}

Keywords: Rural revitalization, Issues relating to agriculture, Rural areas, Rural people, Urban-rural integration.

\section{INTRODUCTION}

The strategy of rural revitalization is a major strategic concept of the Communist Party of China to build a modern and powerful country in the new era, a major initiative to solve the major contradictions in the new era of China, a fundamental issue concerning agriculture and rural farmers, and a fundamental issue concerning the people's livelihood of the country. We must always take the solution of the issues relating to agriculture, rural areas, and rural people as the top priority of the work of the whole party, whether agriculture is strong, the beauty of the countryside and the wealth of farmers determine the quality of a well-off society and the quality of socialist modernization. Compared with the previous agriculture-related strategies, the rural revitalization strategy emphasizes more on the priority development of rural areas and agriculture, which is also the essence of the rural revitalization strategy.

\section{CURRENT SITUATION OF RURAL DEVELOPMENT IN JILIN PROVINCE}

The imbalance between urban and rural development is the most serious imbalance in China's social development, and the inadequacy of rural development is the most serious inadequacy in social development, so the development of rural areas in Jilin Province also confirms this imbalance and inadequacy. At present, Jilin Province has encountered bottlenecks in the process of implementing the rural revitalization strategy. The long-standing urban-rural dual structure has caused the problem of low level of development in rural Jilin Province. By the end of 2019, there were 9,322 administrative villages in the province's rural areas, with a total population of 11.280 million, and the proportion of agricultural machinery operations to the sown area was $80.4 \%$. The per capita disposable income in rural Jilin Province was 14,936.05 yuan in 2019[1], while the per capita disposable income in urban areas was 2.1 times higher than that in rural areas. This shows that there is a large gap between urban and rural development.

In terms of agricultural production, traditional agricultural farming and livestock production are the main activities of rural production, and the relationship between people and land remains the basic economic relationship. Jilin Province has a wide range of agricultural natural resources and agricultural economic resources available. The level of agricultural development in Jilin Province reached the basic realization stage in 2018, but there is still a gap from the pioneering realization stage, and there are differences 
and imbalances in the level of development of agricultural modernization in various regions. In response, the province is actively promoting the first to achieve agricultural modernization, the implementation of green agricultural development, deepening rural reform, etc. In terms of ecological environment, the three-year action plan for rural habitat improvement is being implemented to strengthen the protection of rural ecological environment, accelerate the supply of public services, and improve the quality of life of rural residents.

\section{PROBLEMS IN THE IMPLEMENTATION OF RURAL REVITALIZATION STRATEGY IN JILIN PROVINCE}

\subsection{Single Agricultural Industrial Structure}

Agriculture in Jilin Province presents the problem of single industrial structure. In 2019, plantation and animal husbandry in Jilin Province together accounted for $92 \%$ of the total agricultural output value, while the proportion of forestry and fishery was only $2.75 \%$ and $1.6 \%$ respectively, with a huge difference between the industries of agriculture, forestry, animal husbandry and fishery, among which forestry and fishery still have much room for development, and many agricultural industrial resources have not been reasonably developed.

In addition, the homogenization of the agricultural industry structure is serious, the eastern, central and western parts of the resource advantages have their own characteristics, but the province's planting industry is dominated by corn, the lack of other kinds of cash crops, the agricultural structure is seriously imbalanced. At present, corn, the most important cash crop is also currently facing the problem of large inputs and low economic efficiency, which is due to the province's land allocation policy by rank and distance has caused the problem of too fragmented and scattered land, which is not conducive to large mechanical production, this fragmentation of land management and scattered operations seriously restrict the development of the province's agricultural scale, mechanization, standardization and industrialization.

\subsection{Lack of Non-agricultural Industries}

Rural Jilin Province has the conditions for the development of secondary and tertiary industries: the annual crop growth cycle and the implementation of mechanized production in recent years, so that farmers have only two months of the annual agricultural busy period role, sufficient time can be used by them to develop non-agricultural industries. However, at present, except for a few typical villages, the development potential of secondary and tertiary industries in most rural areas has not been fully released. Compared with wage income, property income and transfer income, the share of farmers' business income in total income is still high, which indicates that farmers lack other channels to increase their income.

The lack of non-agricultural industries is mainly due to the following reasons. Firstly, the general lack of business culture in the Northeastern China, the traditional thought of valuing agriculture shackles farmers. Secondly, lack of active guidance from the government, farmers' willingness to develop secondary and tertiary industries is weak. Furthermore, the low level of rural economy, the lack of collateral for farmers and the cumbersome loan procedures lead to the poor financing ability of farmers. Finally, the lack of financial underwriting policies leads to poor risk tolerance of farmers.

\subsection{Imbalance of Labor Force Structure}

China's rural areas are at an absolute disadvantage in terms of resource factors due to the long-standing urban-rural dual structure and urban-biased development strategy, this resource depression and value depression has put rural Jilin Province in a state of net population outflow. The gender and age structure of the countryside is severely deformed, although the hollowing out of the countryside is consistent with the urbanization process. The proportion of young and strong laborers who go to the city to carry their families is not high. Therefore, most of those left in the rural areas of our province are elderly people, women and children with low labor levels, and such a demographic structure leads to insufficient accumulation of human capital. This not only greatly restricts the promotion and utilization of science and technology, but also makes it difficult to support the construction of a new modernized countryside.

In addition, this demographic structure also makes the weakness of rural grassroots governance prominent. The imbalance in age structure has caused rural grassroots managers to be older, less educated, lacking in governance skills, and slow to accept new things. Some grassroots managers also have problems such as formalism and bureaucracy. Sometimes making it difficult for basic rural construction needs to be met, let alone governance innovation. In short, this imbalanced workforce structure has seriously restricted rural development and rural revitalization. 


\section{COUNTERMEASURES FOR REALIZING RURAL REVITALIZATION IN JILIN PROVINCE}

\subsection{Promote the Priority Development of Agriculture and Rural Areas}

Agriculture and rural farmers are fundamental issues related to the people's livelihood of the country. At no time can we ignore agriculture, forget about farmers, indifferent to rural areas. There is currently tremendous potential for rural development, and much can be done at the grassroots level in the agricultural sector. The most fundamental way to narrow the gap between urban and rural areas to realize rural revitalization is to promote the flow of urban and rural resources and industrial integration. To establish an interactive mechanism of urban-rural coupling, so that urban and rural areas can achieve equal and co-prosperous development.

In order to break the barrier of urban-rural dual structure, more public resources should be given priority to agriculture and rural areas. To adhere to the priority development of agriculture and rural areas and accelerate the modernization of agriculture and rural areas, we must effectively "give priority to rural areas in terms of cadres, give priority to rural areas in terms of factor allocation, give priority to rural areas in terms of capital investment, give priority to rural areas in terms of public services, and speed up to make up for the shortcomings of agriculture and rural areas" [2]. Only based on the actual development of agriculture and rural areas, from the objective conditions and realistic basis, can we create happiness for farmers.

\subsection{Create an Integrated Agricultural Industry System}

In order to promote the scale, mechanization and industrialization of agricultural production, the government should actively build a land transfer platform, so that rural collective construction land and state-owned land can be equally listed, at the same price and with the same rights, and to guarantee farmers fair income from land appreciation. At the same time, the structural reform on the supply side of agriculture should be promoted in depth. Each region should rely on its own advantageous characteristics of resources, and tap the special industries such as Chinese herbal medicine, forest frogs and fresh corn to promote the adjustment of agricultural industry structure. To make bigger and stronger advantageous characteristics of agricultural industries at the same time to avoid industrial homogeneity, so that key industries to form a large-scale development trend, will be made into a scale of the characteristics of industry.
To optimize the province's agricultural big but not strong situation, we must continue to actively tap the development of high-quality brands of special agricultural products, the implementation of the brand strategy to strengthen agriculture. Promote the development of Jilin rice, corn, ginseng, edible mushrooms and other special brands of Jilin, expand the influence of these agricultural brands, and actively build a modern agricultural industrial park. At the same time, develop leisure agriculture and green agriculture, such as agritainment, forestry and fishery, create special agricultural products industrial park, and cultivate new economic growth point of primary industry. Promote farmers' entrepreneurship and employment through industrial development to broaden income generation channels and rural revitalization.

\subsection{Promote the Integrated Development of Three Industries}

As a large agricultural province, the development of rural Jilin Province should rely on its own advantages, according to local conditions, and avoid the shortcomings. Not only should we firmly grasp the advantages of the primary industry, but also make up for the shortcomings of the secondary and tertiary industries. To give full play to the comparative advantage of the primary industry, it should be based on the local black soil resources and green agricultural products advantage. It should also extend the industrial chain of agricultural products, absorb the upstream and downstream industries such as deep processing of agricultural products, ecological farm carnival and agricultural products subscription, develop the secondary industry to increase the added value of agricultural products, and form a large-scale effect. In addition, it should also establish an e-commerce system and modern logistics system based on the agricultural advantage industry to promote the transformation and upgrading of traditional agriculture.

Promote the integrated development of rural primary, secondary and tertiary industries, to give full play to the decisive role of the market allocation of resources, while better play the role of the government. For instance, the province can develop the tertiary industry by tapping the local cultural tourism connotation according to regional conditions, especially by vigorously developing rural tourism with northeastern characteristics and developing various forms of cultural tourism services such as picking cultural festivals, poultry subscription, corn maze, and skiing vacations. The essence of rural industrial integration is the fusion and renewal of old industries under new economic and technological conditions. The rich land elements and ecological advantages of the countryside combine with the capital elements and scientific and technological advantages of the city will complement each other to help farmers 
broaden their income channels. Only through multifaceted efforts and increased industrial linkage can a new pattern of integrated development of rural three industries be formed.

\subsection{Implementation of Talent Path}

Talent path is an important path to realize rural revitalization. Rural revitalization should not only fully stimulate the existing talents in the countryside, but also attract people from all walks of life to build a new countryside. In addition to relying on the family sentiment of talents, it is also necessary for the government to establish a sound incentive mechanism to form a policy highland. Not only should urban laborers and college students be guided to return to their hometowns for employment and entrepreneurship, but elites should also be attracted to flow to the countryside and build new rural areas.

In addition, at the level of rural governance, it is necessary to cultivate rural grassroots managers that understands agriculture, loves the countryside, and loves farmers. Increase the cultivation of professional management personnel and improve the service security capacity of rural professionals. Improve the cultural quality, governance level and innovation ability of grassroots managers, so that they have the will and ability to inject vitality into rural development. These village leaders promote the development of agricultural industrialization while improving the effective structure of rural governance. In this way, we can really let the elite talents to give full play to the stage of the countryside, and let the farmers' entrepreneurs grow and develop in the countryside [3]. Let the talents work together to promote the industrialization of agriculture, lead the farmers to work together to promote the industrialization of agriculture, and improve the effective structure of rural governance.

\section{CONCLUSION}

This study analyzes the special characteristics of regional agricultural production and resource elements in accordance with the overall goal requirements of rural revitalization strategy, deeply analyzes the main problems faced by rural revitalization in Jilin Province, and explores its practical path. It has certain significance for the relevant research and practice of rural revitalization in Jilin, and is practically operable.

\section{REFERENCES}

[1] Jilin Provincial Bureau of Statistics, Jilin Statistical Yearbook, China Statistics Press, 2020.

[2] Bo Yuan,Opinions of the State Council of the Central Committee of the Communist Party of China on the implementation of rural revitalization strategy, in: People's Daily,2018,DOI:http://data.people.com.cn/member /login?iu=/rmrb

[3] Xinhua News Agency, Xi Jinping: development is the first priority, talent is the first resource, and innovation is the first driving force.2018, DOI: http://www.xinhuanet.com/politics/201803/07/c_1122502719.htm 